Check for updates

New York, USA

Cite this as: BMJ 2020;371:m4064 http://dx.doi.org/10.1136/bmi.m4064 Published: 20 October 2020

\section{Covid-19: Fauci awarded for "unprecedented public service" while Trump fires more insults}

\author{
Janice Hopkins Tanne
}

The US National Academy of Medicine has awarded Anthony Fauci, director of the National Institute of Allergy and Infectious Diseases (NIAID), its first Presidential Citation for Exemplary Leadership.

At its virtual annual meeting on 19 October, the academy cited Fauci's "unprecedented public service" for nearly 40 years at NIAID; as "trusted advisor to six US presidents during public health crises including HIV/AIDS, severe acute respiratory syndrome (SARS), anthrax, influenza, and Ebola; and firm and steady leadership during the covid-19 pandemic.” Fauci has provided "an unwavering, trusted voice to the nation and world on behalf of science based policy and public health," the academy added.

Presidential citations are awarded to public service figures to recognise distinguished achievement.

But in his latest call to his supporters, president Donald Trump aimed criticism at Fauci. He said, "People are tired of covid. I have these huge rallies. Just leave us alone. They're tired of it. People are tired of hearing Fauci and all these idiots.” 12

As of 19 October, more than 8200 ooo people in the US have been infected with covid-19, 220088 people have died, ${ }^{3}$ and cases are rising in almost all states and Washington, DC. 4

Fauci, speaking on a panel on the state of the pandemic at the academy meeting, said the world had been dealing with coronaviruses for decades-the four common cold viruses, plus SARS, Middle East respiratory syndrome, and now covid-19.

“This will happen again," he said, calling for the development of a strong global health network and the rebuilding of the US public health system.

Fauci said that the US had never gone down to a baseline level of infection before reopening its economy. If it had stuck to the proposed 14 day downward trend before reopening, it would have made a significant difference. "There was a feeling that public health measures were an obstacle to opening the economy." he said. Opening led to a surge of infections that made containment and control difficult. "We could have done it by using 'safe and prudent measures' such as wearing masks, social distancing, and avoiding crowded indoor settings," he said.

Some $40-45 \%$ of infected people are asymptomatic but can nevertheless spread the infection, so these measures are critical, Fauci said. About $81 \%$ of covid-19 infections are mild, $14 \%$ severe, and 5\% critical; mortality is around $2.3 \%$. Because the risk is higher for older people and those with comorbidities, about $40 \%$ of US adults are susceptible.
Chikwe Ihekweazu, head of the Nigeria Centre for Disease Control, told the meeting that the control he had seen in China would be hard to implement in other countries that lacked China's social systems to deliver food and medicine to people in quarantined cities and to support local businesses.

Fauci said, "We can't get to something approaching normal without a vaccine." He was, however, "cautiously optimistic" that one would be available in mid-November or early December. But because only about half of Americans have said they would take a vaccine, it is essential to engage communities "that have inherent mistrust of government," he added.

Drawing on his experience during the HIV/AIDS epidemic, Fauci said that messages from governments must be consistent and updated to reflect new information to restore trust.

Nicole Lurie, a member of the Coalition for Epidemic Preparedness Innovations and a former assistant secretary at the US Department of Health and Human Services, told the meeting that there was hesitancy among African American, Latino, Native American, and other minority communities because of history such as the Tuskegee experiment. Communication through trusted community leaders was essential in reaching such groups, she said.

Listen to leaked call of Trump bashing Fauci to his staff. CNN. 19 October 2020. www.cnn.com/videos/politics/2020/10/19/trump-campaign-callfauci-disaster-vpx.cnn.

2 Bowden E, Nelson S. Trump on Twitter piles on Anthony Fauci over first pitch, covid-19 response. New York Post. 19 October 2020. https://nypost.com/2020/10/19/trump-piles-on-fauci-over-first-pitch-and-covid-19response.

3 Covid-19 dashboard by the Center for Systems Science and Engineering at Johns Hopkins University. https://gisanddata.maps.arcgis.com/apps/opsdashboard/index.html\#/bda7594740fd40299423467b48e9ecf6.

4 Covid in the US: latest map and case count. New York Times. 2020. www.nytimes.com/interactive/2020/us/coronavirus-us-cases.html. 